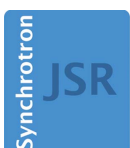

JOURNAL OF SYNCHROTRON RADIATION

ISSN 1600-5775

Received 4 February 2021

Accepted 4 February 2021

Keywords: Daresbury Laue software source code



\section{Weblinks for the Daresbury Laue software source code and information. Addendum}

\author{
Quan Hao, ${ }^{\mathrm{a} *}$ Marjorie M. Harding, ${ }^{\mathrm{b} *}$ John R. Helliwell ${ }^{\mathrm{c} *}$ and D. Marian Szebenyi ${ }^{\mathrm{d} *}$ \\ ${ }^{\mathbf{a}}$ School of Biomedical Sciences, University of Hong Kong, Hong Kong, ${ }^{\mathbf{b}}$ Centre for Translational and Chemical Biology, \\ University of Edinburgh, Michael Swann Building, Mayfield Road, Edinburgh EH9 3JR, United Kingdom, 'Department of \\ Chemistry, University of Manchester, Manchester M13 9PL, United Kingdom, and dMacCHESS, Cornell University, \\ Ithaca, New York, USA.*Correspondence e-mail: qhao@hku.hk, marjorieharding80@gmail.com, \\ john.helliwell@manchester.ac.uk,dms35@cornell.edu
}

The weblinks for the Daresbury Laue software source code and information have become hidden from a simple google search. This Addendum makes clear where the software source code and information can now be found.

The software source code (identical versions) may be downloaded from any one of the following three weblinks:

https:/www.chess.cornell.edu/sites/default/files/inline-files/

Daresbury_laue.tar.gz

https://zenodo.org/record/4381992\#.X-B7Z1DgrtQ

http://web.hku.hk/ qhao/Daresbury_laue_Dec2020.tar.gz

The weblink for the full information about the suite is now https://web.archive.org/web/20001024010254/http://www. dl.ac.uk/SRS/PX/jwc_laue/laue_top.html.

As a very brief recap, the recording and analysis of synchrotron Laue diffraction data were described in Helliwell et al. (1989). The finalised wavelength normalisation was described in Arzt et al. (1999), and the finalised integration in Campbell et al. (1998) includes the adaptations made for neutron Laue diffraction data collection. A summary article of the numerous benchmark applications with synchrotron radiation was Nieh et al. (1999), to which this addendum is attached. The conversion of the source code for use with neutron sources has been made at the Institut Laue Langevin and the Oak Ridge National Laboratory reactor and spallation sources. Access to those versions are at the discretion of those facilities. The principal funding sources involved were the UK's Science and Engineering Research Council (SERC) and the Engineering and Physical Sciences Research Council (EPSRC), Principal Investigator (PI): M. M. Harding, and Co-PI: J. R. Helliwell.

\section{References}

Arzt, S., Campbell, J. W., Harding, M. M., Hao, Q. \& Helliwell, J. R. (1999). J. Appl. Cryst. 32, 554-562.

Campbell, J. W., Hao, Q., Harding, M. M., Nguti, N. D. \& Wilkinson, C. (1998). J. Appl. Cryst. 31, 496-502.

Helliwell, J. R., Habash, J., Cruickshank, D. W. J., Harding, M. M., Greenhough, T. J., Campbell, J. W., Clifton, I. J., Elder, M., Machin, P. A., Papiz, M. Z. \& Zurek, S. (1989). J. Appl. Cryst. 22, 483-497.

Nieh, Y. P., Raftery, J., Weisgerber, S., Habash, J., Schotte, F., Ursby, T., Wulff, M., Hädener, A., Campbell, J. W., Hao, Q. \& Helliwell, J. R. (1999). J. Synchrotron Rad. 6, 995-1006. 